\title{
COMMENTARY
}

\section{Care of adult women with Turner syndrome: the state of affairs in Germany}

\author{
Mette H Viuff ${ }^{1}$ and Claus H Gravholt ${ }^{1,2}$ \\ 'Department of Molecular Medicine, Aarhus University Hospital, Aarhus, Denmark \\ ${ }^{2}$ Department of Endocrinology, Aarhus University Hospital, Aarhus, Denmark
}

Correspondence should be addressed to C H Gravholt: ch.gravholt@dadlnet.dk

\begin{abstract}
In this commentary, we discuss the state of affairs concerning the clinical care of females with Turner syndrome (TS) in Germany. TS is a rare disease and new international guidelines describe an appropriate setup for optimal clinical care. Several countries have implemented a program with centralized adult Turner syndrome clinics, which are now found in France, Denmark, the Netherlands, Sweden, parts of England and possibly other countries, but hitherto not in Germany. Such an approach should ensure the availability of high quality multi-disciplinary care for all women with TS to be treated and to detect all the conditions that have been associated with TS, which typically appear at odd times during the lifetime of a female with TS. Care should be offered at no added cost for the patient, and treatment with relevant drugs should be available at reasonable cost for the individual patient. Currently, it is quite problematic that many female sex hormone preparations are not available at low cost in a number of countries. Additional problems include supply chain issue which lead to patients not being able to buy their usual drug for a certain period of time. We think it is timely that countries improve the care for individuals with rare conditions, such as TS.
\end{abstract}

Endocrine Connections (2019) 8, C1-C4
Turner syndrome (TS) is a condition with a missing $\mathrm{X}$ chromosome $(45, \mathrm{X})$ or parts thereof or with a mosaic setup $(45, X / 46, X X$ or other variants). It is a rare disease. New international guidelines describe an appropriate setup for optimal clinical care (1). Several countries have implemented a program with centralized adult Turner syndrome clinics, which are now found in France, Denmark, the Netherlands, Sweden and parts of England and possibly other countries. This should ensure the availability of high-quality multidisciplinary care for all women with TS to be treated and to detect all the conditions that have been associated with TS, which typically appear at odd times during the lifetime of a female with TS. Care should be offered at no added cost for the patient, and treatment with relevant drugs should be available at reasonable cost for the individual patient. Currently, it is quite problematic that many female sex hormone preparations are not available at low cost in a number of countries. For example, transdermal drugs such as gels or patches are not available in all countries or are only available at high costs. Additional problems include supply chain problems that many times lead to patients not being able to buy their usual drug for a certain period of time.

When the child with TS has finished treatment in the pediatric department, usually consisting of growth hormone treatment for promoting linear growth and induction of puberty to ensure appropriate development of secondary sex characteristics and neurocognitive development in line with peers, transitioning to an adult care taker will take place. This sounds like an easy task. However, in relation to TS, as is the case in relation to many other rare and even common conditions as well, transition has proven to be troublesome, and several 
studies have documented that many patients 'disappear' in an apparent gap between pediatric and adult care $(1,2,3)$.

It is also well documented that many patients will have undetected morbidity, which is only diagnosed once they are seen at a dedicated multidisciplinary clinic $(4,5,6)$. Although it may at first glimpse seem easy to care for females with TS - 'would one not just have to substitute the missing female sex hormone?' you might think. The reality is that many times it can be exceedingly difficult. This is because TS is a syndrome - and as is the case with any other syndrome, lots of other conditions, diseases, socioeconomic circumstances, neurocognitive and psychologic challenges, issues with fertility, and the frequent need for ovarian egg donation, makes its necessary for the anchor person (being the pivotal physician) to be able to achieve a holistic picture of the condition. In other words, this anchor physician is the pivotal physician who coordinates care, most often an endocrinologist, needs to have a comprehensive understanding of the syndrome and should be willing to take on this obligation (7). This, in order to direct the patient to the services that can be needed in another medical specialties (8).

Why is diagnosis of TS many times so tricky? Well, for one, most physicians still have the textbook image of a prototypical girl or woman with TS in the back of their mind and think that they can easily diagnose all females they encounter with possible TS. By now, however, numerous papers clearly show that this is not the case. In epidemiologic studies of TS the average age at diagnosis is around 15 years (9), and only rather few are picked up by prenatal screening programs (10). In a large clinical study, the average age at diagnosis was not much lower, but was dependent on karyotype -45 , X females typically being diagnosed earlier (11), while in another clinical study from Australia the median age at diagnosis was also 15 years (12). This illustrates that diagnosis is much more difficult than many clinicians believe. Our current approach, which is dependent on presenting clinical features which in turn leads to referral to a pediatrician, does not work, and many females with TS are only diagnosed during adult life. This leaves some adult TS on a diagnostic odyssey, especially those with an atypical phenotype, which is frequent among those only being diagnosed late, because adult caretakers are not that familiar with diagnosing TS. In fact, we think the only diagnostic avenue in the future will be to include TS, along with other sex chromosome abnormalities, in neonatal screening programs (13). This would allow complete diagnosis of TS without diagnostic delay.
In the November 2019 issue of Endocrine Connections, a paper was published on the current state of affairs in Germany in relation to adult care of TS (14). This paper paints a rather gloomy and grim picture of current standards of care for adult women with TS. We think the authors should be commended for publishing their results and their analysis of why it is so in Germany. It is not that we should think that Germany is an especially dark spot on the international horizon of care for patients with rare diseases, but rather that this case illustrates many of the problems that one is faced with when attempting to build a national and reputable service for an under-served patient population. The authors retrospectively document in five non-university endocrine centers in Germany that adult care was focused on endocrine manifestations of TS, while clinical features including cardiovascular disease, renal and liver involvement, autoimmune diseases, hearing loss, and osteoporosis were not focused on. The authors do not even discuss neurocognitive assessments, which often would not have been performed. In essence, this report shows much the same results as other previous retrospective analyses in other countries concerning the level of care $(3,4,5,12,15,16)$.

Surprisingly, karyotype was present in only $50 \%$ of the investigated cases. Since karyotype is essential for assessing the pattern of comorbidities, a verified diagnosis is essential to initiate or continue treatment. In order to avoid multiple karyotype testing, a possible solution could be establishment of a national cytogenetic registry, which is present in the Nordic countries, in order to retrieve the karyotype for further adult care, and importantly also, for research purposes.

Since mortality due to cardiac conditions is continuously elevated in Turner syndrome (17), the fact that only $43 \%$ underwent cardiac examination and only $8 \%$ had an MRI, shows that improvements are warranted. The new guidelines recommend that all TS individuals should be thoroughly investigated in order to prevent aortic rupture or progression of aortic stenosis and to avoid development off ischemic heart disease (1).

The authors also describe an initiative some years ago toward creating adult TS clinics in Germany, which did not become a success, for which the authors have no explanation. However, now there is another push in Germany for the creation of adult Turner syndrome centers, which was initiated in March 2019 and most likely will improve care for TS women in Germany. Much of the undetected additional morbidity being diagnosed in dedicated TS clinics should be preventable

This work is licensed under a Creative Commons Attribution-NonCommercial-NoDerivatives 4.0 Internationab License.ifica. com at 04/26/2023 11:00:14AM 
with appropriate education of patients and physicians alike. In addition, Kahlert et al. found that up to $20 \%$ of their surveyed TS females were not receiving hormone replacement therapy, which is likely the treatment with the greatest health benefit in TS $(7,14)$. In a recent nationwide study in Denmark, we also identified nontreatment with hormone replacement therapy as being present in varying percentages of patients depending on karyotype (18) and furthermore documented more pronounced morbidity among non-users. The report by Kahlert et al. deals with 258 adult females with TS $(1.6 \%$ of all women with TS in Germany) out of a combined population of an estimated 16,000 women with TS in Germany, and an estimated 115,000 women with TS in the EU (14). Suffice to say, currently only a fraction of these women has even received a diagnosis! In other words, there is a pressing need for better, more systematic care of TS, but also EU-wide and preferably world-wide registries in order to better collect comprehensive longitudinal data on individuals with TS concerning genotype-phenotype relations in an international setting. Many hypotheses could and should be tested in such a setting.

The creation of European Reference Networks (ERN), and especially the European Reference Network on Rare Endocrine Conditions (ENDO-ERN) within the EU, should prove to be a leveraging mechanism for ensuring equal level and accessibility of care, as well as quality of life, fertility, optimal care etc., promote cross-border research within the EU (and eventually also outside of the EU) in basic mechanisms and other aspects of TS, as well as other disorders of sex development (DSDs) (19).

In conclusion, the paper by Kahlert et al. highlights the overall problematic state of the current level of care for adults with TS within the EU, but probably even more pronounced outside the EU except perhaps a country like Australia, and the need to implement nationwide programs.

\section{Declaration of interest}

The authors declare that there is no conflict of interest that could be perceived as prejudicing the impartiality of this commentary.

\section{Funding}

This work did not receive any specific grant from any funding agency in the public, commercial, or not-for-profit sector.

\section{Author contribution statement}

$\mathrm{M} \mathrm{HV}$ and $\mathrm{CH}$ G wrote this editorial together. (c) 2019 The authors Published by Bioscientifica Ltd

\section{References}

1 Gravholt CH, Andersen NH, Conway GS, Dekkers OM, Geffner ME, Klein KO, Lin AE, Mauras N, Quigley CA, Rubin K, et al. Clinical practice guidelines for the care of girls and women with Turner syndrome: proceedings from the 2016 Cincinnati International Turner Syndrome Meeting. European Journal of Endocrinology 2017 177 G1-G70. (https://doi.org/10.1530/EJE-17-0430)

2 Rubin K. Transitioning the patient with Turner's syndrome from pediatric to adult care. Journal of Pediatric Endocrinology and Metabolism 200316 (Supplement 3) 651-659.

3 Ertl DA, Gleiss A, Schubert K, Culen C, Hauck P, Ott J, Gessl A \& Haeusler G. Health status, quality of life and medical care in adult women with Turner syndrome. Endocrine Connections 20187 534-543. (https://doi.org/10.1530/EC-18-0053)

4 Freriks K, Timmermans J, Beerendonk CC, Verhaak CM, NeteaMaier RT, Otten BJ, Braat DD, Smeets DF, Kunst DH, Hermus AR, et al. Standardized multidisciplinary evaluation yields significant previously undiagnosed morbidity in adult women with Turner syndrome. Journal of Clinical Endocrinology and Metabolism 201196 E1517-E1526. (https://doi.org/10.1210/jc.2011-0346)

5 Nabhan ZM \& Eugster EA. Medical care of girls with Turner syndrome: where are we lacking? Endocrine Practice 201117 747-752. (https://doi.org/10.4158/EP11059.OR)

6 Devernay M, Ecosse E, Coste J \& Carel JC. Determinants of medical care for young women with Turner syndrome. Journal of Clinical Endocrinology and Metabolism 200994 3408-3413. (https://doi. org/10.1210/jc.2009-0495)

7 Gravholt CH, Viuff MH, Brun S, Stochholm K \& Andersen NH. Turner syndrome: mechanisms and management. Nature Reviews: Endocrinology 201915 601-614. (https://doi.org/10.1038/s41574-0190224-4)

8 Lin AE, Prakash SK, Andersen NH, Viuff MH, Levitsky LL, RiveraDavila M, Crenshaw ML, Hansen L, Colvin MK, Hayes FJ, et al. Recognition and management of adults with Turner syndrome: from the transition of adolescence through the senior years. American Journal of Medical Genetics: Part A 2019179 1987-2033. (https://doi. org/10.1002/ajmg.a.61310)

9 Berglund A, Viuff MH, Skakkebaek A, Chang S, Stochholm K $\&$ Gravholt CH. Changes in the cohort composition of Turner syndrome and severe non-diagnosis of Klinefelter, $47, \mathrm{XXX}$ and 47,XYY syndrome: a nationwide cohort study. Orphanet Journal of Rare Diseases 201914 16. (https://doi.org/10.1186/s13023-018-0976-2)

10 Viuff MH, Stochholm K, Uldbjerg N, Nielsen BB, Danish Fetal Medicine Study Group \& Gravholt CH. Only a minority of sex chromosome abnormalities are detected by the Danish national prenatal screening program for Down syndrome. Human Reproduction 201530 2419-2426. (https://doi.org/10.1093/humrep/dev192)

11 Cameron-Pimblett A, La RC, King TFJ, Davies MC \& Conway GS. The Turner syndrome Life Course Project: karyotype-phenotype analyses across the lifespan. Clinical Endocrinology 201787 532-538.

12 Vincent AJ, Nguyen HH, Ranasinha S \& Vollenhoven B. Increased detection of co-morbidities with evaluation at a dedicated adult Turner syndrome clinic. Climacteric 201720 442-447. (https://doi. org/10.1080/13697137.2017.1350841)

13 Grosse SD, Rogowski WH, Ross LF, Cornel MC, Dondorp WJ \& Khoury MJ. Population screening for genetic disorders in the 21st century: evidence, economics, and ethics. Public Health Genomics 201013 106-115. (https://doi.org/10.1159/000226594)

14 Kahlert E, Blaschke M, Brockmann K, Freiberg C, Janssen OE, Stahnke N, Strik D, Merkel M, Mann A, Liesenkotter KP, et al. Deficient knowledge in adult care as an incentives for founding Turner centers in Germany. Endocrine Connections 20198 1483-1492. (https://doi.org/10.1530/EC-19-0418)

15 Pedreira CC, Hameed R, Kanumakala S \& Zacharin M. Health-care problems of Turner syndrome in the adult woman: a cross sectional
This work is licensed under a Creative Commons Attribution-NonCommercial-NoDerivatives 4.0 International License ifica com at $04 / 26 / 2023$ 11:00:14AM 
study of a Victorian cohort and a case for transition. Internal Medicine Journal 200636 54-57. (https://doi.org/10.1111/j.14455994.2005.00990.x)

16 Ucar A, Abaci A, Pirgon Ö, Dundar B, Tutunculer F, Catli G, Anik A, Kılınç Uğurlu A, Buyukgebiz A \& Turner Study Group. A synopsis of current practice in the diagnosis and management of patients with Turner syndrome in turkey: a survey of 18 Pediatric Endocrinology Centers. Journal of Clinical Research in Pediatric Endocrinology 201810 230-238. (https://doi.org/10.4274/jcrpe.0003)

17 Mortensen KH, Andersen NH \& Gravholt CH. Cardiovascular phenotype in Turner syndrome - integrating cardiology, genetics, and endocrinology. Endocrine Reviews 201233 677-714. (https://doi. org/10.1210/er.2011-1059)

18 Viuff MH, Berglund A, Juul S, Andersen NH, Stochholm K \& Gravholt $\mathrm{CH}$. Sex hormone replacement therapy in Turner syndrome - impact on morbidity and mortality. Journal of Clinical Endocrinology and Metabolism 2019. (https://doi.org/10.1210/clinem/dgz039)

19 Hiort O, Cools M, Springer A, McElreavey K, Greenfield A, Wudy SA, Kulle A, Ahmed SF, Dessens A, Balsamo A, et al. Addressing gaps in care of people with conditions affecting sex development and maturation. Nature Reviews: Endocrinology 201915 615-622. (https:// doi.org/10.1038/s41574-019-0238-y)

Received in final form 12 November 2019

Accepted 20 November 2019

Accepted Preprint published online 21 November 2019 (c) 2019 The authors Published by Bioscientifica Ltd 